\title{
Exploring Accessibility Scenarios for 2020 in Relation with Future ICT Trends on Assistive Technology and Accessibility
}

http://dx.doi.org/10.3991/ijim.v6i1.1790

\author{
C. Kouroupetroglou, D. Tektonidis, A. Koumpis, I. Ingnatiadis \\ ALTEC Software SA, Thessaloniki, Greece
}

\begin{abstract}
In this paper we are going to present a set of 5 future scenarios that were developed within the eAccessibility2020 study. The study aims to explore and analyse the referred relationships between the emerging ICT landscape, in the societal and economic context and the development and provision of assistive technologies (AT) and eAccessibility, within a perspective of 10 years. The scenarios were developed after an initial trend analysis that the study team conducted based on data gathering. The scenarios were developed based on a methodology which defined a set of guides for scenario development and a set of visions for the future of eAccessibility.
\end{abstract}

Index Terms-Accessibility, Assistive technologies, Scenarios, Trends.

\section{INTRODUCTION}

This paper will present of a set of initial scenarios prepared for the eAccessibility[1] study needs. The scenarios developed were based on a data gathering process and the outcomes from the initial trend analysis that the study team conducted based on the gathered data. The data gathering process of the study is a process and the following trend analysis were based on two main axes: The desk research and interviews with experts.

\section{A. Desk research}

Desk research included reading and categorization of a large set of conference and journal research papers, EU funded RTD project deliverables and various trend analysis reports. The collected material was analyzed and categorized into groups according to the technology used, disability/ies addressed, and beneficiaries. Additionally, during the desk research, the study team selected a set of 137 EU funded RTD projects relevant to eAccessibility and eInclusion as a base for other parts of the research. This analysis which is now in its latest stages produced some preliminary outcomes of technologies that seem possible to have an impact on accessibility in the future.

\section{B. Interviews}

Out of 137 projects related to eAccessibility and eInclusion the study team has selected a set of 46 projects relevant either to the projects goals or to technologies that were already identified as trends from the desk research. Next, we contacted about 130 persons that participated in those projects by email and asked for their participation in an interview regarding their views for the future of accessibility from their filed of expertise. Almost 30 of them replied and were scheduled for an interview. Until now 23 of them have already been conducted. The interviews objective was twofold. The first one was to get the experts opinions in the future of their area of expertise in relation to eAccessibility. The second was to investigate experts' opinions on the future of eAccessibility in general.

\section{PRE-SCEnARio DeVElopment Methodology}

In this initial scenario-building attempt we have roughly explored what could be the future in 2020 (and particularly in terms of the available ICTs, societal/ demographic conditions, etc.) Then we have examined the desirable future in terms of eAccessibility (i.e. the technology and market environment that would 'best' fit to the users and society's needs), with an eye on the feasibility aspect of such future (feasibility is posing a set of technology and socio-economic limitations on the 'best' desirable future)

Therefore, there have been three main directions and limitations in the process of scenario building, which are summarised below:

- What is desirable? (user \& policy perspective)

- What is feasible? (technology and socio-economic perspective)

- What is the time dimension? 2020 - 2025 when research results reach the market

The scenario development methodology was based on a set of high level theoretical scenarios that were used as guides for the development of more specific scenarios

\section{A. High-level pre-scenarios}

Under the scoping phase of the study ideas on initial broad scenarios (high-level scenario guides) have been put forward. These ideas were used (together with the three abovementioned directions/ limitations) as a starting point for the study. They have slightly changed during our work until today (i.e. end of July 2011) and may radically change in the future.

In any case, they will be further broken down to cover also different situations/ aspects of life (e.g. working life, mobility, etc.), the severity of disability, etc. Similarly, the study team may prioritise eAccessibility solutions based on the Maslow hierarchy of (human) needs to ensure they are in line with the potential value they create (e.g. solutions addressing health issues are normally of higher importance than gaming applications).

Also, economic factors such as cost reductions in the private sector (especially among enterprises operating websites or offering software), which may affect the 
budget allocated to eAccessibility solutions and compliance with relevant standards will be taken into consideration. Finally, issues of high importance such as mainstreaming eAccessibility, etc. will be explored.

\section{1) Technology-driven scenario guide.}

Scenarios built based on the first high level scenario guide may focus on a prevalent in 2020 type of ICT applications (such smart mobile applications). The eAccessibility-related user needs will be dictated by these applications (e.g. the way they are used, the interfaces they have, the services they offer, the type of user interaction they require, etc.). Also, another similar scenario may be built upon a technology-breakthrough hypothesis e.g. in brainmachine interaction and thus examine the eAccessibility future in this respect.

\section{2) Disability-driven scenario guide.}

Scenarios built based on that high level scenario guide will focus on an expected major disabilities for 2020 (e.g. cognitive disability, etc.). Under this perspective, the scenario will examine how technological and other factors may affect eAccessibility solutions supporting this specific (types of) disabilities.

\section{3) User-group-focused scenario guide.}

Scenarios built based on the user-group-focused scenario guide will focus on a major target group for eAccessibility in 2020 such as elderly people. Similarly, the prescenario may examine how technological and other factors may evolve to offer a range of eAccessibility solutions on this target group. The potential influence of progress in medicine and health sciences may also be assessed.

\section{B. Visions for the Future of eAccessibility}

Apart from having the three high level scenario guides the study team has also produced a set of visions for the future of eAccessibility based on the interaction with user representatives and eAccessibility stakeholders. These visions serve as targets that the scenarios should achieve by following some of the previously presented guides.

\section{1) Vision 1: Accessibility Benefits All}

This vision supposes that by 2020 the perception that accessibility is aimed at a minority group will be broken. Therefore all stakeholders will then acknowledge that accessibility is a high value-added activity that benefits all groups. This will result in a variety of eAccessibility solutions which in turn will offer better design choices. Having eAccessibility solutions mainstreamed, career options will be improved and productivity will rise not just for disabled users.

\section{2) Vision 2: Full Spectrum eAccessibility for Elderly Persons}

The second vision supposes that by 2020 there will be universal appreciation of the fact that capabilities decline with age for all people. Thus, systems will need to be designed for ease of use by all people regardless of their physical limitations. This will preserve people's quality of life and professional productivity enabling late retirement and high quality of life long after retirement.

\section{3) Vision 3: Publish for All}

In this vision we suppose that by 2020 all publications will be available in friendly format for disabled people. This will be achieved by the uptake of accessible, consumer friendly content production models by all major publishing companies. Publishing of accessible content will not include only text but audio and video content as well and all content produced will be compatible with all major standards such as WCAG \& DAISY etc.

\section{4) Vision 4: Tools for All}

This last vision supposes that by 2020 basic tools such as calendars, agendas, calculators, spreadsheets, databases, etc. Will have far superior functionality based on Universal Design/ Design for All principles. This will be achieved by the wide spread of basic programmatic tools, such components, libraries, APIs etc that will be accessible in first place. This way using core programmatic components that are built with accessibility in mind the production of accessible web apps, mobile apps, desktop apps etc will become far easier. This means that new applications will have even more enhanced ease of use for all users.

\section{The five initial scenarios}

In the following sections we elaborate on five initial scenarios that can be regarded as indicative of the possible extrapolations that one can make given a specific vision as those described previously and taking into account various parameters related to the use of technology (available or not yet, existing or not mature), the linkage with a particular disability or, finally, a specific user group.

TABLE I.

CLASSIFICATION OF THE FIVE PRE-SCENARIOS WITH RESPECT TO THEIR RELATION TO THE FOUR VISIONS AND THE ORIENTATION REGARDING TECHNOLOGIES, DISABILITIES AND USER GROUP FOCUS.

\begin{tabular}{|c|c|c|c|c|c|}
\hline 芦 & 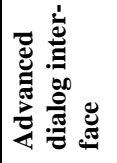 & 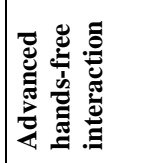 & 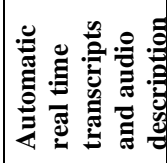 & 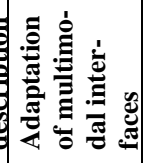 & 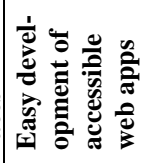 \\
\hline$\ddot{\ddot{\theta}}$ & $\begin{array}{l}\text { Vision 1: } \\
\text { Accessi- } \\
\text { bility } \\
\text { Benefits } \\
\text { All }\end{array}$ & $\begin{array}{l}\text { Vision 1: } \\
\text { Accessibil- } \\
\text { ity Benefits } \\
\text { All }\end{array}$ & $\begin{array}{l}\text { Vision 2: } \\
\text { Full Spec- } \\
\text { trum eAcces- } \\
\text { sibility for } \\
\text { Elderly Per- } \\
\text { sons }\end{array}$ & $\begin{array}{l}\text { Vision 3: } \\
\text { Publish for } \\
\text { All }\end{array}$ & $\begin{array}{l}\text { Vision 4: } \\
\text { Tools for } \\
\text { All }\end{array}$ \\
\hline 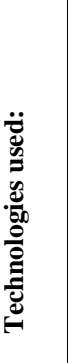 & $\begin{array}{l}\text { Speech } \\
\text { recogni- } \\
\text { tion, } \\
\text { NLP, } \\
\text { TTS, } \\
\text { Ad- } \\
\text { vanced } \\
\text { IR }\end{array}$ & $\begin{array}{l}\text { Gaze recog- } \\
\text { nition, face } \\
\text { recognition, } \\
\text { brain- } \\
\text { computer } \\
\text { interfaces }\end{array}$ & $\begin{array}{l}\text { Speech rec- } \\
\text { ognition, } \\
\text { NLP, new } \\
\text { metadata } \\
\text { enabled } \\
\text { video and } \\
\text { multimedia } \\
\text { formats, } \\
\text { Smart home } \\
\text { devices such } \\
\text { as TV }\end{array}$ & \begin{tabular}{|l} 
Mobile \\
device, \\
user profil- \\
ing, adap- \\
tive mul- \\
timodal \\
interfaces
\end{tabular} & $\begin{array}{l}\text { Reusable } \\
\text { compo- } \\
\text { nents, open } \\
\text { source } \\
\text { libraries, } \\
\text { web apps, } \\
\text { adaptive } \\
\text { multimodal } \\
\text { interfaces }\end{array}$ \\
\hline 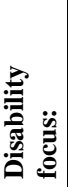 & $\begin{array}{l}\text { Visual, } \\
\text { mobility, } \\
\text { cogni- } \\
\text { tive, } \\
\text { elderly }\end{array}$ & Mobility & $\begin{array}{l}\text { Visual, hear- } \\
\text { ing, multiple } \\
\text { disabilities. }\end{array}$ & $\begin{array}{l}\text { All dis- } \\
\text { abilities }\end{array}$ & $\begin{array}{l}\text { All disabili- } \\
\text { ties }\end{array}$ \\
\hline 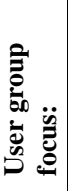 & $\begin{array}{l}\text { Elderly, } \\
\text { every- } \\
\text { body }\end{array}$ & $\begin{array}{l}\text { Motor- } \\
\text { impaired, all }\end{array}$ & $\begin{array}{l}\text { Elderly, } \\
\text { everybody }\end{array}$ & $\begin{array}{l}\text { All user } \\
\text { groups }\end{array}$ & $\begin{array}{l}\text { Application } \\
\text { Developers }\end{array}$ \\
\hline
\end{tabular}




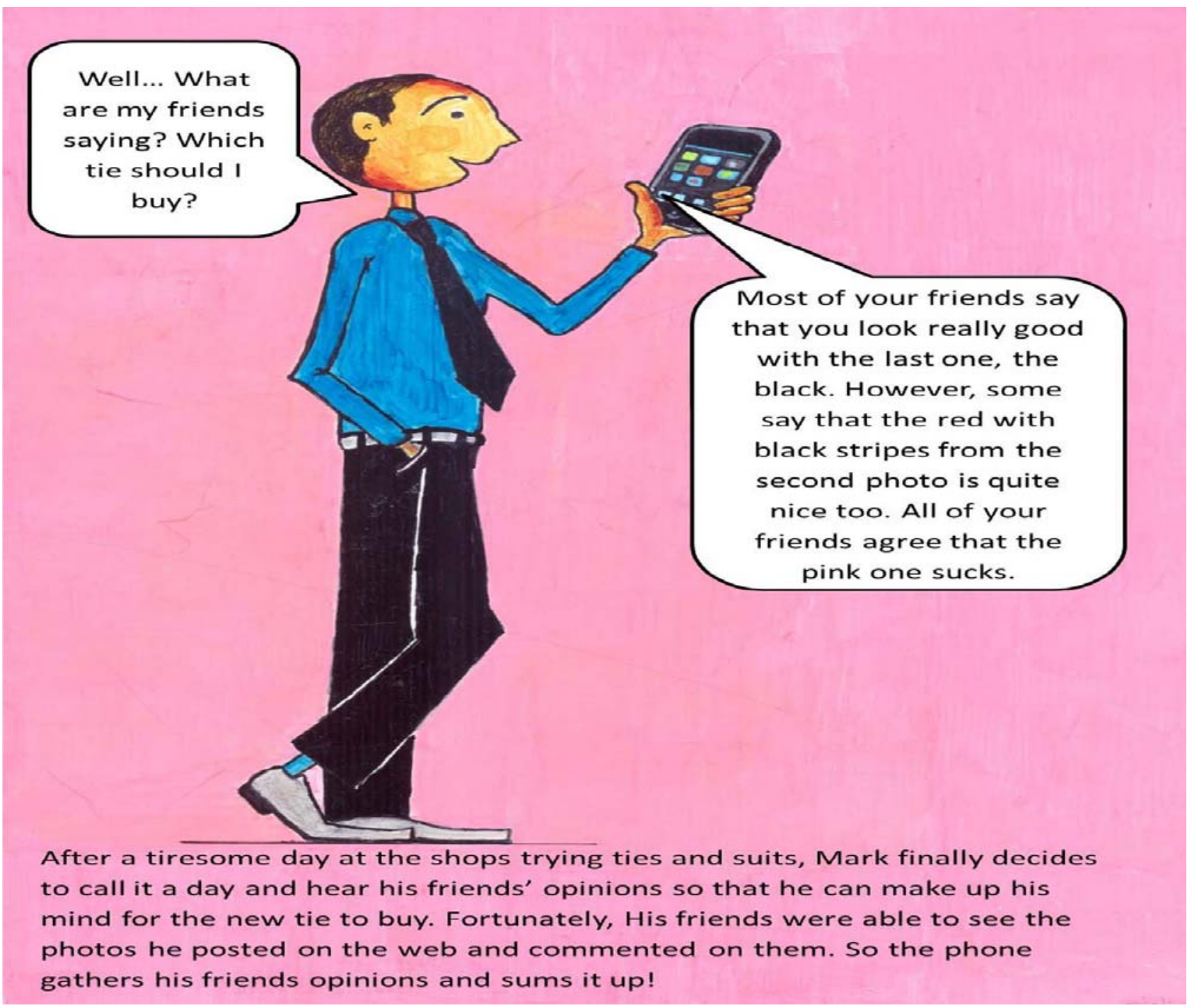

Figure 1. Scenario: "I am having a conversation with my mobile device”

Given the analysis of trends the high level scenarios and the visions for the future already presented so far, in the following section we attempt to combine them under five scenarios.

These scenarios have been built after a brainstorming exercise which intended to investigate possible ICT trends combinations having in mind the visions for the future and the high level scenarios. Thus, we started combining various weak signals, micro and key ICT trends having a specific disability or user groups in mind, in order to produce possible future solutions for them. Using the visions as targets, the scenarios we developed aim to showcase examples of how these visions could be achieved. These scenarios can be seen as examples of the final scenarios that will be produced in the next stages and evaluated for their validity and plausibility.

The first part of each scenario introduces the technologies exploited and the second part describes the scenario in the form of a story involving imaginative people and situations in the future.

\section{PRE-SCENARIO: AdVANCED Dialog InTERFACES}

\section{A. Technologies exploited}

Dialog interfaces are a reality in many situations nowadays. However, they usually work with specific limited vocabulary and in a specific context. Additionally, mobile devices' capabilities are increasing dramatically by the time leading to more powerful tools in users' hands. Technologies related with dialog interfaces such as speech recognition, TTS and NLP are evolving[2] and we already have signals that more advanced interfaces will appear (see IBM Watson). Combining the increase in mobile devices' capabilities with the advances in dialog interface technologies and with the trend of seamless connectivity through mobile networks such as 3G, 4G etc., we can expect more advanced dialog interfaces without limited vocabularies and able to understand idioms, slung, etc of human language to emerge. The latter combined with more intelligent and possibly personalized information retrieval systems can lead to advanced dialog interfaces that will be close to human to human interaction. 


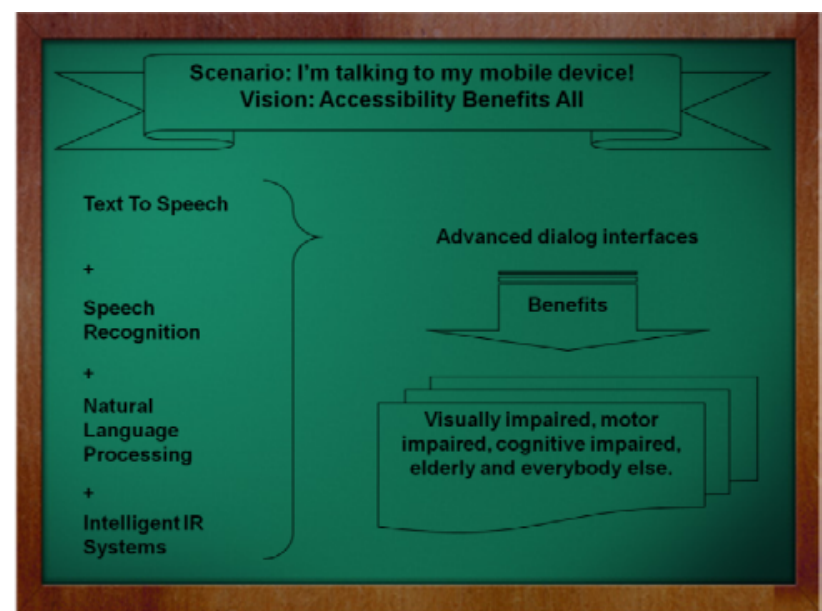

Figure 2. Scenario diagram for advanced dialog interfaces

One of the major disabilities benefiting from dialog interfaces are visually impaired people. However, they are not the only disability group that can benefit from such interfaces. Mobility impaired people or even people with cognitive disabilities might also benefit from such interfaces. Additionally, older people will probably be using mobile devices in the future far more than today and being able to operate with them in a more intuitive way will help significantly in their experience and engagement with new technologies. Thus, the elderly is also a user group with significant benefits from this kind of interaction interfaces. It is also easy to understand that such interfaces would also help everybody in their everyday interaction with various devices in cases where they are situationally visually or mobility impaired (e.g. driving a car).

\section{B. Scenario: "I am having a conversation with my mobile device"}

Mary is a 20 year old blind girl who goes out for shopping. Instead of relying solely on the shopping assistants' opinions' for the new pair of shoes she wants to buy, she tells her phone to ask her friends about the shoes she is trying. The phone automatically uploads the photos to social networks with a related caption such "How do you like it?". After about an hour or two of trying various pairs of shoes and outfits and uploading their photos she asks her phone "What are my friends thinking about the pairs I tried?". The phone and the respective dialog interface realize that she is talking about the latest photos she uploaded and her friends' comments on them, gathers the comments and answers with something like "Most of your friends think the second and fifth pair you tried are cool and awesome and they really didn't like the third pair." The discussion could go on with something like "What is Mark thinking about the fifth pair?" and the phone could answer with something like "He thinks they are great and he likes them the best”. So after a discussion with her phone (actually after a discussion with her friends) she could decide on which pair to buy.

\section{PRE-SCENARIO: ADVANCED HANDS-FREE INTERACTION}

\section{A. Technologies exploited}

One of the technologies identified also as a trend from our data gathering process was Brain-Computer Interfaces (BCI)[3]. Using our brain to control various computer functions seems possible in the future. Such devices seem

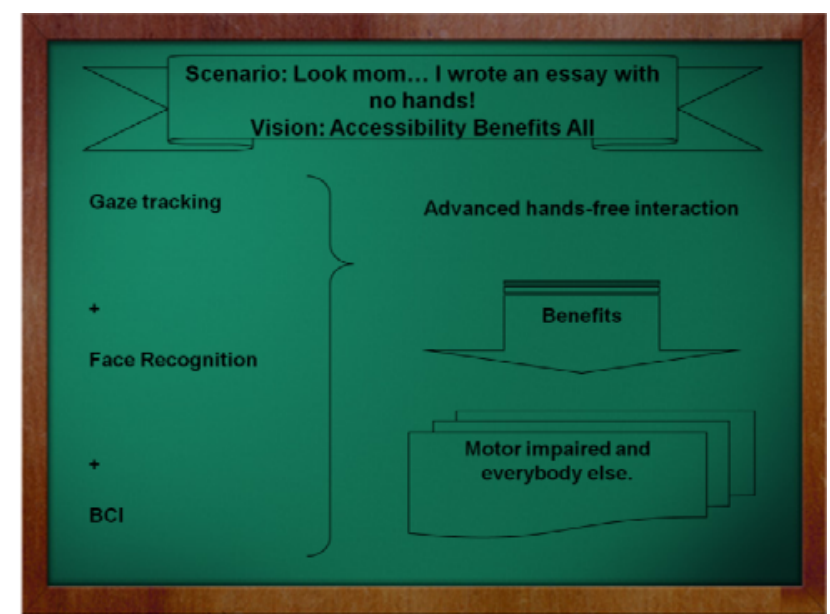

Figure3. Scenario diagram for advanced hands-free interaction

a bit awkward and strange nowadays but mainstreaming of such devices could lead to more user-friendly devices in the form of a baseball cup for example. Users will probably be able to operate them easier than today and this could become a key technology trend in the future. In addition we already have signal of mainstreaming devices and technologies having to do with gesture recognition (i.e. Kinect) which shows the potential of evolvement of such technologies and their enhancement in the core of future device platforms. So an example could be tablets in the future that will have integrated software for gesture and/or face recognition and possibly gaze tracking.

Gestures, face recognition, gaze tracking and brain computer interfaces can all be operated by mobility impaired people and could be really useful for people with serious mobility impairments. Additionally it could also help people that due to their work environment or other circumstances cannot use their hands to interact with an ICT device. The latter could lead to the following use case scenario.

\section{B. Scenario: "Look mom... I wrote an essay with no hands!"}

Andrew is a 14 years old boy who goes to school in his wheelchair due to his serious mobility impairment. He can use his right hand but with limited mobility allowing him though to make specific gestures. He is wearing a baseball cup that however is not like any other ordinary baseball cup. It uses electrodes to read specific brainwaves and transmits them (through Bluetooth/ WiFi/etc.) to the tablet that is constantly connected in his chair. The tablet's camera is always on and tracks Andrew's eyes movements and possible gesture he makes. He returns from school where his history teacher gave them an assignment on World War II. Additionally, using his baseball cup he opens the browser and starts searching for sources and information on his assignment. Then, using the on-screen keyboard with the eye tracking software he starts writing his assignment while at the same time he uses specific face expressions for styling the text he is writing and controlling other functions of the program. When finished with his assignment he thinks of music and through his BCI baseball cup he logs on to his favourite music service and starts listening to it. 


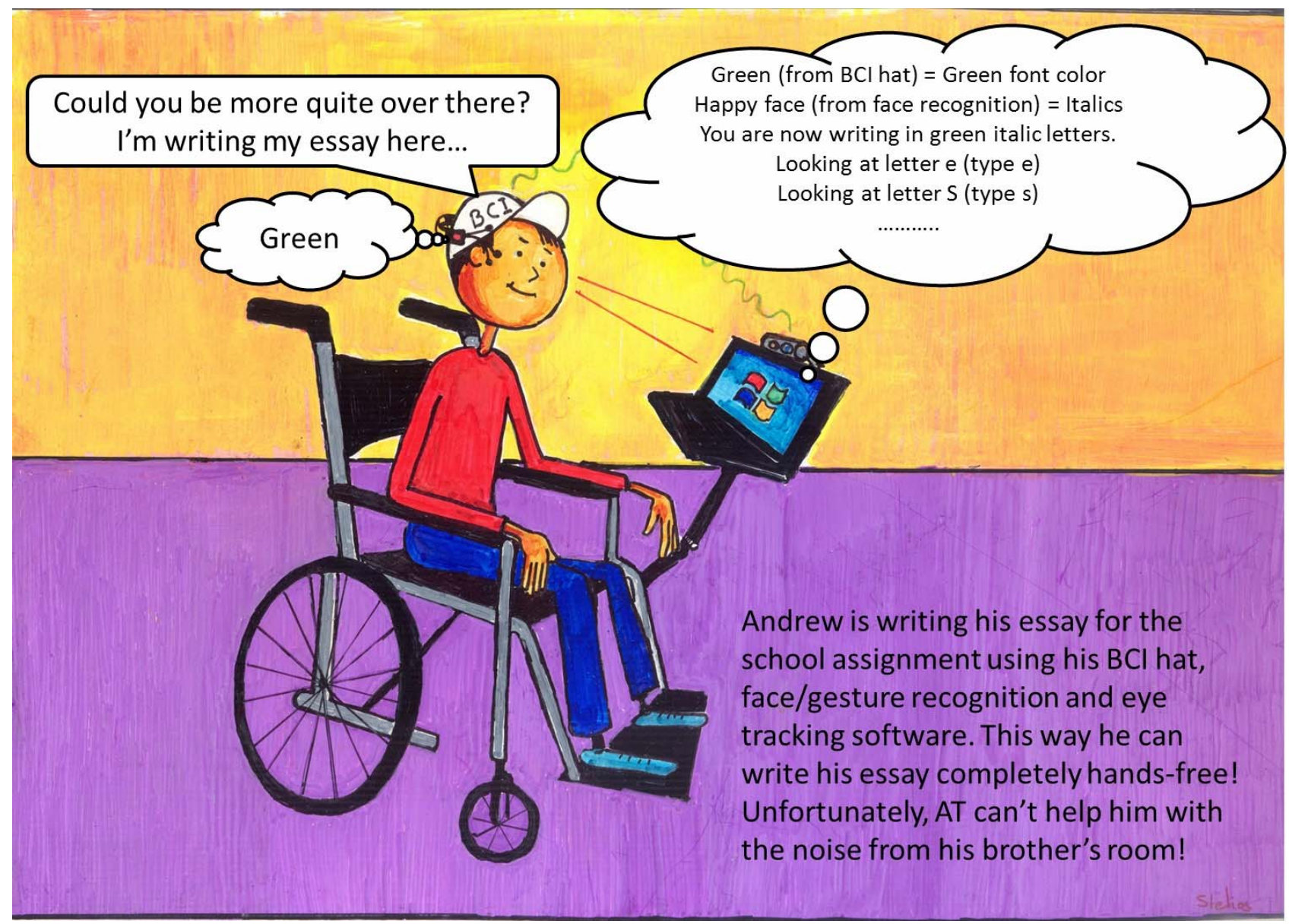

Figure5. Scenario: "Look mom... I wrote an essay with no hands!”

\section{PRE-SCENARIO: AutOMATIC REAL TIME TRANSCRIPTS AND AUDIO DESCRIPTION}

\section{A. Technologies exploited}

Another technology trend identified in the analysis is the use of a variety of devices to access web content and services. People are expected to interact seamlessly with any device in their home which in turn uses web content and apps. Such devices could be tablets, electrical appliances, TVs, smart rooms etc.

One very common device used mainly for recreational purposes is the TV. TVs are now starting to integrate operating systems that allow various apps to run on them and be used by their viewers. The TV is becoming another information access point in the house allowing in parallel the use of appropriate applications and services. Videos which are usually displayed on TV are also changing and new formats are coming out such as webVTT[4] which allow the enhancement of various metadata within the video. So, future movies could come in those new enhanced formats. In addition, developments in speech recognition, NLP and speech technologies in general can help in the easier production of such metadata by studios, but they could also facilitate applications for automatic real time transcripts of a video[5] (see closed captions on youtube). Finally these new video formats can also carry video descriptions which through TTS could be utilised and read to people with visual disabilities.

These new multimedia formats enable the simultaneous use of a variety of interactions during their playtime. This means that a movie coming out in these new formats could be easily watched by a deaf person by reading the transcripts (either already embedded or produced in real time) without any problems. In addition, blind persons could also use the same format of a video to watch the same movie but instead of the transcripts they could use the audio description describing the action on the video. This audio description could be enhanced by the producer or produced on the fly using image recognition software. New TV devices with appropriate apps could use all this information in a video to provide the appropriate interaction to each user.

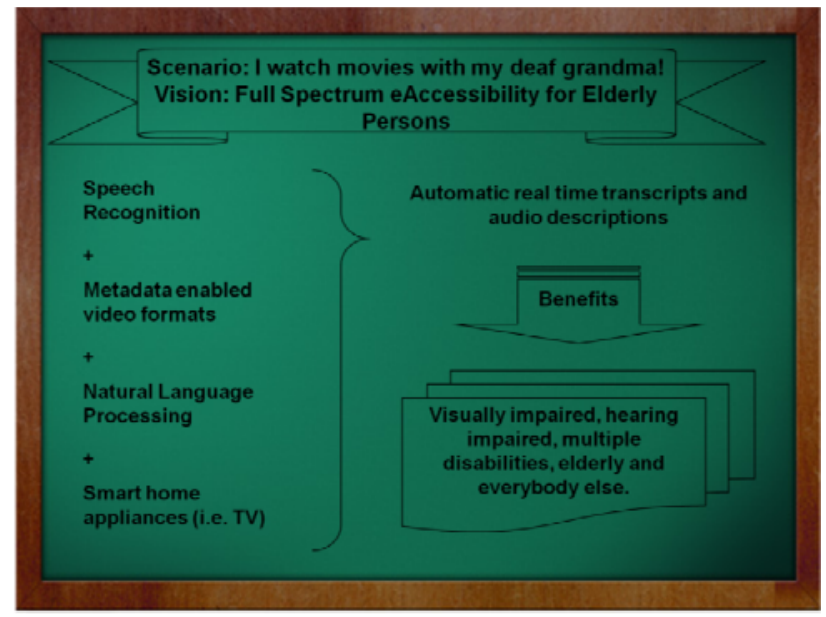

Figure 4. Scenario diagram for automatic real time transcripts and audio descriptions 


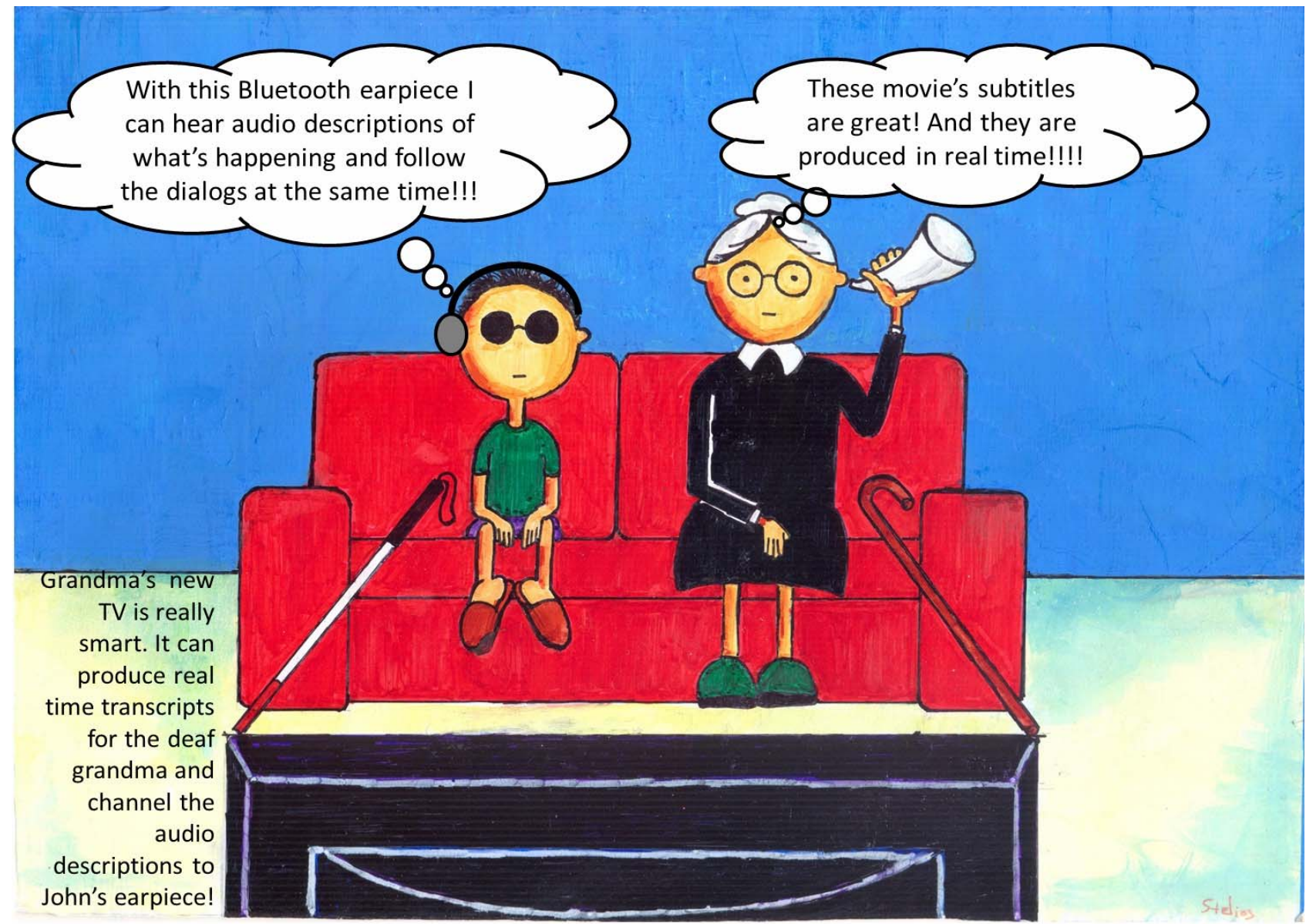

Figure 6. Scenario: "I watch movies with my deaf grandma"

\section{B. Scenario: "I watch movies with my deaf grandma”}

John is a 12 year old boy who loves to watch the movies. Despite his total loss of vision, he uses his new TV with the image recognition software which produces on the fly audio descriptions of his favourite movies. Thus he is able to watch any movie he likes. On the other hand, his 86 year old grandma loves to watch the movies too. However, due to her age she has a hearing impairment and uses an earpiece which she finds very annoying. When she watches the movies on the TV she prefers to turn on the automatic real time transcription feature which places subtitles of what is said in the screen. This weekend John is staying the night at his grandma's place. They decide to watch “Mission Impossible 6". They’ve heard good critics and they are both interested to watch it. They log on to their favourite video service from grandma's new tv and select the film from the large variety provided. They sit back on the couch and for the next two hours they enjoy the movie. Grandma is watching it on the TV with the transcripts provided by the producer company and John uses his Bluetooth earpiece to hear the audio description while the movie is playing.

\section{PRE-SCENARIO: AUTOMATIC ADAPTATION OF MULTIMODAL INTERFACES}

\section{A. Technologies exploited}

The use of mobile devices is becoming more and more vital day by day. Modern smart phones can contain a lot of information about users, such as documents, music, preferences for various applications and so on. So, having a personal profile on a mobile device seems quite natural for the future of ICT. In addition, mobile phones are enhanced with connectivity sensors which allow them to interact with other machines through WiFi, Bluetooth, NFC etc. Finally, they are also enriched with a variety of sensors, such as GPS, camera, light sensors, movement sensor etc. which allow them to recognise the context where they are used. This means that mobile devices can recognise their context of use and can easily connect to a variety of other ICT devices such as computers, info kiosks, ATMs etc. Additionally, a trend identified in the study is multimodal interfaces[6] which adapt to users' needs. Having a personal profile stored on phone or even in the cloud and communicating it with other devices can make this adaptation much easier and provide users with a seamless interaction among many devices.

Obviously multimodal interfaces can be used by many people with different disabilities and different degrees for disabilities. Having a world where every human-machine interaction is adapted according to users' needs is also a vision for the future. However, the study reveals that apart from having multimodal adaptive interfaces, assistive technologies will always play a significant role since design for all cannot be easily achieved in all cases. This means that a solution of a mobile phone speaking out user's needs to various ICT devices can be used in many ways. It could lead to user interface adaptation according to user needs (enabling screen reader), or it could also lead to user interface adaptation to allow interaction with specific AT used by the user. 


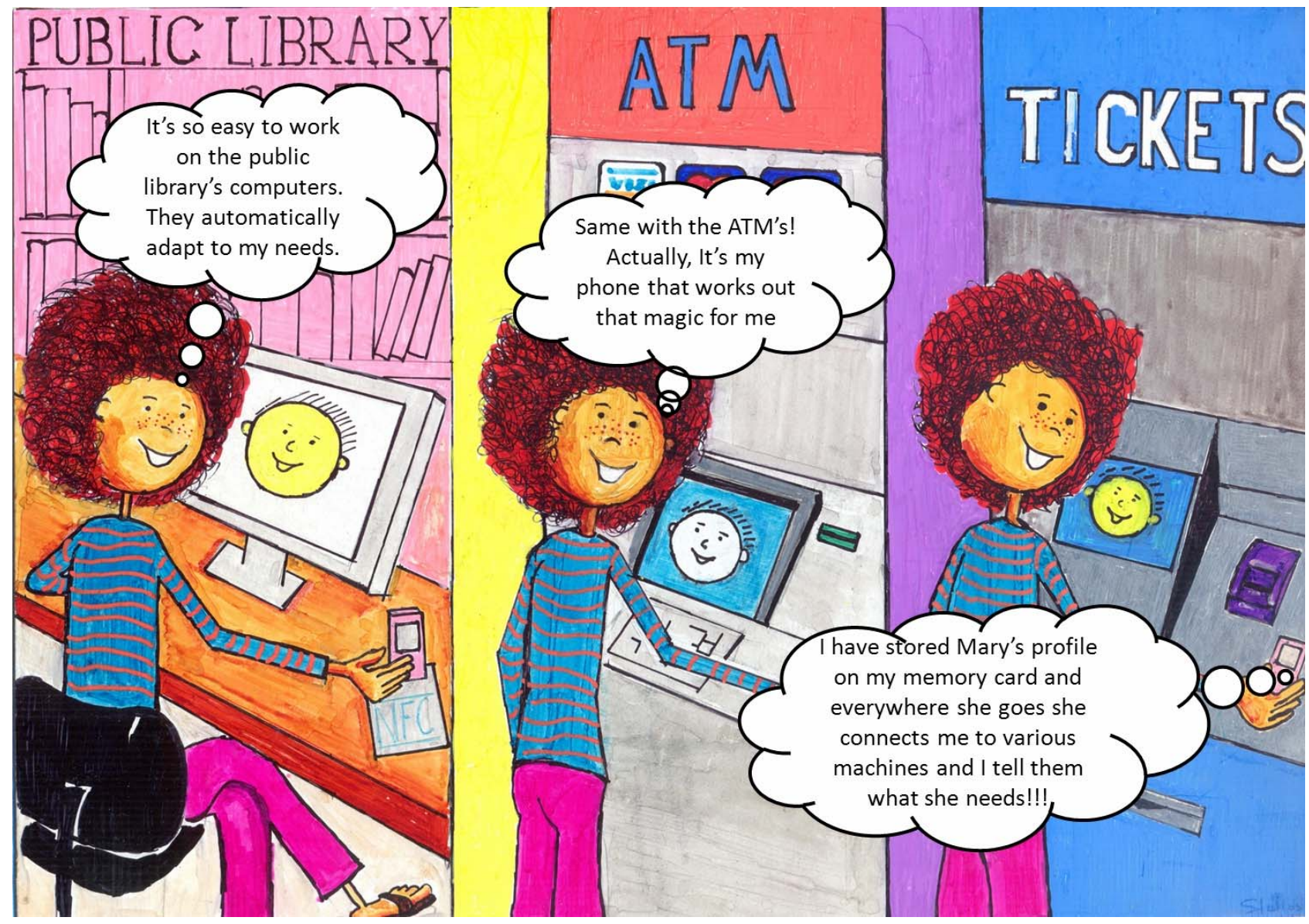

Figure 8. Scenario: "My phone speaks out for me"

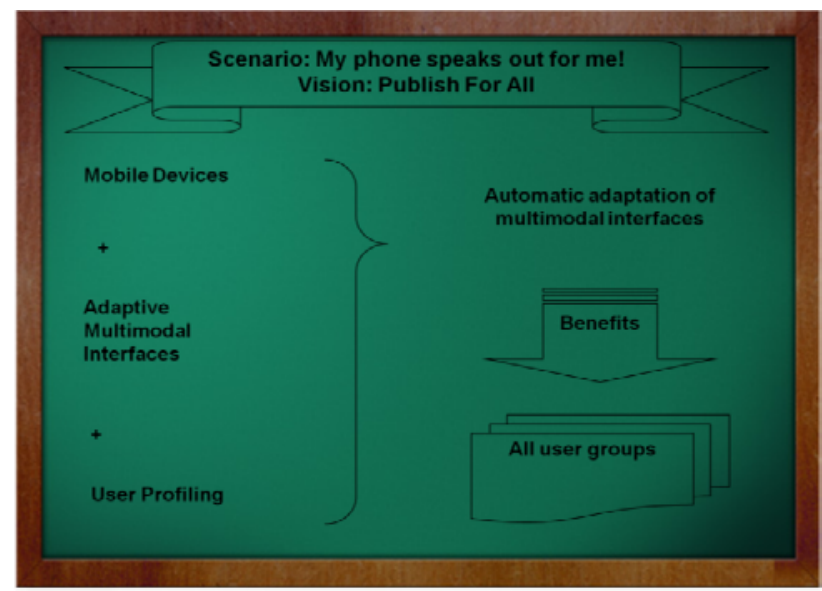

Figure 7. Scenario diagram for automatic adaptation of multimodal interfaces

\section{B. Scenario: "My phone speaks out for me"}

Mary, the 20year old girl from the first scenario goes to her universities library to use a computer to work on her new assignment. She always carries with her a Bluetooth earpiece and her mobile phone. When sitting in front of the library's computer she places her phone on top of an NFC connector which identifies her to the computer and gives the appropriate information needed for the user's interface adaptation. The computer automatically opens up the screen reader, and since the computer is used in a public library, finds through the phone the Bluetooth earpiece used by Mary and sends the audio input to it. Simultaneously the phone recognises Mary is in a library and goes automatically in silent mode. Mary can now log on to the machine and start working on her assignment.

On the same day, Andrew from the second scenario goes out for shopping and wants to use an ATM to withdraw some money. When approaching with his wheelchair the ATM, his mobile phone automatically recognises through WiFi the ATM and asks Andrew if he wishes to connect with it. Andrew answers yes moving his head, the tablet recognises his gesture, connects with the ATM and displays the ATM's interface on the tablet's screen. Andrew places his card in the ATM and completes the withdrawal using the ATM interface through his tablet, which uses face recognition and eye tracking for the interaction. Now he is free to go shopping wherever he wants.

\section{PRE-SCENARIO: EASY DEVELOPMENT OF ACCESSIBLE WEB APPS}

\section{A. Technologies exploited}

This fifth scenario could be tied with Vision 3: Publish for All (which could also be interpreted as "Develop for All) and with Vision 4: Tools for All, because that's what we are aiming too. It could also be tied with legislation about accessibility as a trend.

Our analysis identified ubiquitous connectivity and network services as micro trends together with cloud based services and technologies. Combined with signals from the market such as new web based OS's (see 


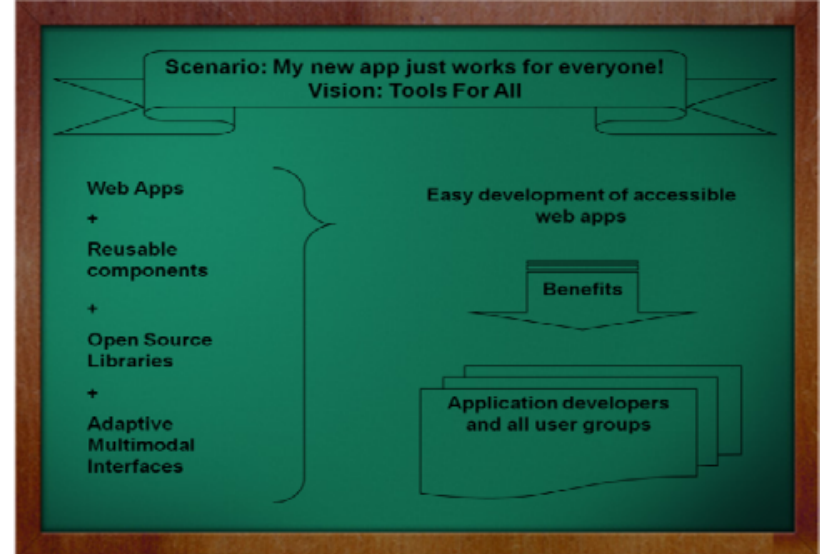

Figure 9. Scenario diagram for easy development of accessible web apps

ChromeOS, JolyCloudetc) it shows that in the coming years there will be an explosion of new web apps that will allow users to use a variety of services through web applications. The development of web apps is becoming easier by the years bringing even more developers to that area. Thus, the need for developing accessible web apps easier would become even more evident[7].

The analysis of our findings shows also that knowing about accessibility and related guidelines doesn't always mean that a developer can make an accessible app. However, a suggestion made by some experts in the interviews was that we should invest on developing core accessible component to be used by developers. For example instead of using a simple calendar widget a developer could have the option to choose between a set of different calendar widgets developed with accessibility in mind. Using such components would allow developers to focus on their app development without having to worry about their accessibility. In addition, it will lead specific developers special- izing and really grasping the accessibility issues to deal with them from the core of development structures: reusable components, open source libraries, web apps, adaptive multimodal interfaces.

The benefits from such a dissemination of roles in the development process will be for every user who will need to use a web app using different interaction modalities. It will also make easier the life of developers who will not have to struggle with accessibility aspects in every detail of their application. It could also lead to an easier adoption of the vision of designing for all since the core components in development will be designed for all.

\section{B. Scenario: "My new app just works for everyone!"}

Peter is a 42 years old web app developer. He develops web applications using a specific set of tools and components that he has learned, tested and grasped really well. In some point of his career he meets George, a blind 35 year old man who tried to use some of his apps but found it very difficult. During their discussion George is telling Peter that he is using another company's applications. The company named "MyD4AApps" is advertising that they use an open source library of basic components that can adapt their interaction modality according to user's needs which are specified during the initial set up of the application. He downloads and starts experimenting with this open source library. After some time reading the documentation and some related tutorials, he builds his first simple web application and sends an email to George to try it out. In some days George returns back with comments not only from himself, but also from a group of other disabled users telling him that the app worked fine with whatever AT and setup they were using. Peter, seeing how easy it is to rely on the library for accessibility issues decides to update the rest of his apps using the new library.

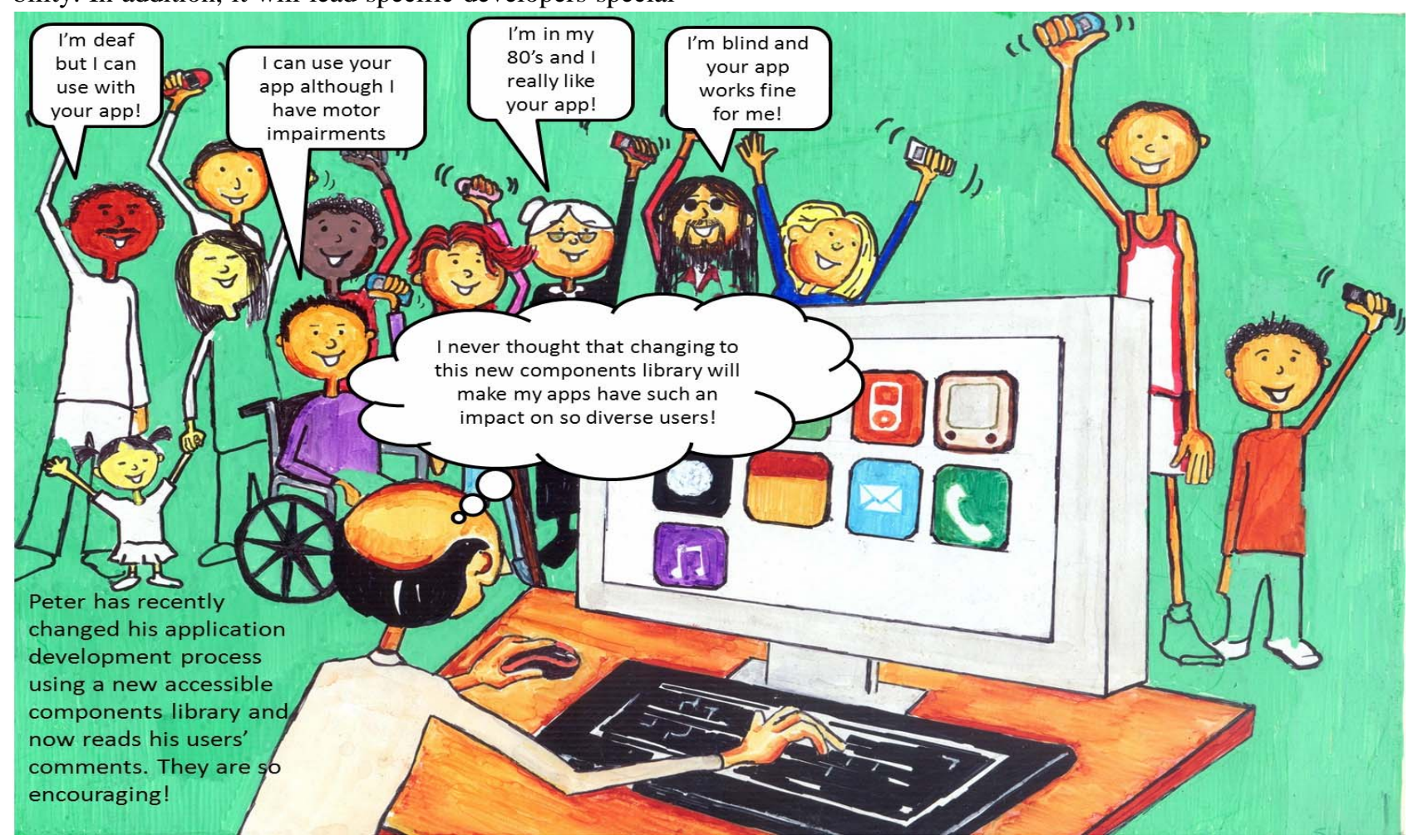

Figure 10. Scenario: "My new app just works for everyone!” 


\section{VIII.FURTHER WORK}

The study's next steps include further production of more scenarios. These scenarios will then be validated by experts on their feasibility and impact in order to be filtered. The best scenarios after the experts' assessment will be used in the final report of the study as suggestions for research policies and specific technologies that the EU should follow and invest on during the coming years to promote and enhance ever further eAccesibility.

\section{REFERENCES}

[1] eAccessibility, http://www.e-accessibility2020.eu/ (accessed on 30/06/2011)

[2] Gilbert, M., \& Junlan Feng, "Speech and language processing over the web”, Signal Processing Magazine IEEE Vol. 25 Issue:3 p18-28, 2008

[3] Brunner, P., Bianchi, L., Guger, C., Cincotti, F. and Schalk, G. , "Current trends in hardware and software for brain - computer interfaces (BCIs)”, J Neural Engineering, Vol. 8 Number 2, 2011. http://dx.doi.org/10.1088/1741-2560/8/2/025001

[4] WebVTT, http://www.whatwg.org/specs/web-apps/current-work/ webvtt.html (accessed on 30/06/2011)

[5] Ogata, J., Masataka, G. and Kouichirou, E.,, "Automatic transcription for a web 2.0 service to search podcasts", In Spoken Language For all, Antwerp, INTERSPEECH, 2007, pp.2617-2620.

[6] Nicu, S., "Multimodal interfaces: Challenges and perspectives”, $J$. Ambient Intelligence and Smart Environments, Vol 1, Issue 1, pp23-33, 2009

[7] Mikovec, Z., Vystrcil, J. and Slavik, P., "Web toolkits accessibility study”, SIGACCESS Access. Comput., Issue 94, pp. 3-8, June, 2009.

\section{AUTHORS}

C. Kouroupetroglou holds a PhD in Applied informatics since 2010 from University of Macedonia in Thessaloniki. His PhD research focused on web accessibility, investigating the impact of a semantic web based mechanism in blind users' browsing experience.

Apart from working in research programs funded by various organisations (Greek Ministry of Education, EU, etc.) he is also teaching in the Alexander Technological Institute (ATEI) of Thessaloniki as a scientific associate. (e-mail: chris.kourou@gmail.com).

Dimitris Tektonidis holds a BSc in Software Engineering and a $\mathrm{PhD}$ in Computer Science for research in the area of Enterprise Application Integration. His main fields of research are Enterprise Application Integration (EAI), IS interoperability, Service Oriented Architectures (SOA), Web Services, Semantic Web, e-Commerce, eGovernment and Enterprise Systems (ERP, CRM, SCM). (e-mail: dte@altec.gr).

Adamantios Koumpis heads the Research Programmes Division of ALTEC S.A., which he founded at 1996 (then as independent division of Unisoft S.A.). Adamantios holds a PhD degree from the University of Kingston, UK and a Bachelor degree from the University of Crete, Greece. (email: akou@altec.gr).

Dr Ioannis Ignatiadis has a $\mathrm{PhD}$ in Information Systems from the University of Bath in the UK, as well as undergraduate and MSc degrees in IT and Technology Management.

He has extensive industrial experience as a software consultant in information technology projects for large European multinationals. He also worked as a senior researcher in the implementation of EU Information Society Technologies (IST) projects, notably the LAURA FP5 and the PANDA projects. His research interests evolve around the technical, social and organizational aspects of the development and use of enterprise systems, e-business and service-oriented architecture solutions (email: jignatiadis@googlemail.com).

Work reported here has been funded by the European Commission, DG Information Society and Media, ICT addressing societal challenges, ICT for Inclusion as part of the study on e-Accessibility2020 ("Study on Implications from Future ICT Trends on Assistive Technology and Accessibility”, SMART 2010/0077). The study is presented at www.eaccessibility2020.eu.

Submitted, August 15, 2011. Published as resubmitted by the authors December 14, 2011. 